\title{
Article
}

\section{Sustainable Management for Fresh Food E-Commerce Logistics Services}

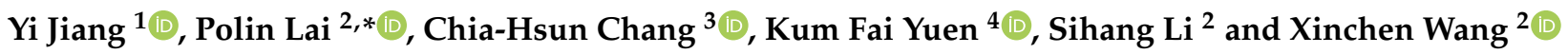 \\ 1 Department of Economics, Chung-Ang University, Seoul 06974, Korea; jyhgzy123@cau.ac.kr \\ 2 Department of International Logistics, Chung-Ang University, Seoul 06974, Korea; \\ baronshjang@foxmail.com (S.L.); taemin130129@naver.com (X.W.) \\ 3 Liverpool Logistics, Offshore and Marine Research Institute (LOOM) and Maritime and Mechanical \\ Engineering, School of Engineering, Liverpool John Moores University, Liverpool L3 3AF, UK; \\ c.chang@ljmu.ac.uk \\ 4 School of Civil and Environmental Engineering, Nanyang Technological University, \\ Singapore 639798, Singapore; kumfai.yuen@ntu.edu.sg \\ * Correspondence: polin@cau.ac.kr; Tel.: +82-02-820-5848
}

Citation: Jiang, Y.; Lai, P.; Chang, C.-H.; Yuen, K.F.; Li, S.; Wang, X. Sustainable Management for Fresh Food E-Commerce Logistics Services. Sustainability 2021, 13, 3456. https:// doi.org/10.3390/su13063456

Academic Editor: Arkadiusz Kawa

Received: 19 February 2021

Accepted: 16 March 2021

Published: 20 March 2021

Publisher's Note: MDPI stays neutral with regard to jurisdictional claims in published maps and institutional affiliations.

Copyright: () 2021 by the authors. Licensee MDPI, Basel, Switzerland. This article is an open access article distributed under the terms and conditions of the Creative Commons Attribution (CC BY) license (https:// creativecommons.org/licenses/by/ $4.0 /)$.

\begin{abstract}
This article determines the quality factors which improve the satisfaction of logistics services, and the specific evaluation items that customers value. Moreover, this study verifies the moderating effect of consumers on the perceived importance of last-mile logistics services, and its impact on logistics service satisfaction. Through a literature review, the conceptual model is determined, and measurement scales are developed. Furthermore, we collect data through online surveys and employ structural equation modeling, hierarchical regression analysis, and importance-performance analysis methods in order to analyze the collected data, and to test the research hypotheses. The findings of this study are as follows. First, the qualities of personal contact, timeliness, and empathy in the fresh food e-commerce logistics service quality evaluation system have a significant positive impact on the fresh food e-commerce logistics service consumer satisfaction, but the delivery quality and information quality are not significant. Second, consumers' perceived importance of last-mile logistics services has a positive and significant impact on the consumer satisfaction of fresh food e-commerce logistics services. Moreover, as a moderating variable, its moderating effect has limitations: it only affects the relationship between information quality, timeliness quality, empathy quality, and consumer satisfaction. Finally, in the three evaluation dimensions of information quality, timeliness quality, and empathy quality, specific items that need to be further improved are identified. This study enriches and supplements the empirical research in the field of fresh food e-commerce logistics, and provides academic literature with a reference value for fresh food e-commerce logistics enterprises.
\end{abstract}

Keywords: fresh food e-commerce; last-mile logistics; logistics service quality; perceived importance

\section{Introduction}

The overall e-commerce transaction volume is increasing year by year, and the ecommerce platform has become an important channel for consumers. China's fresh food e-commerce market maintained a steady growth of $29.2 \%$ in 2019 , reaching US $\$ 162$ billion. It is expected to exceed US $\$ 260$ billion in 2020, and to reach US $\$ 310$ billion by 2021 [1]. Due to the global outbreak of COVID-19, the increasing penetration rate of e-commerce, and the development of user behavior habits, the growth rate of the fresh food e-commerce market is forecast to be far higher than expected. Therefore, the fresh food e-commerce platform is an important field of consumer online shopping.

Cold chain technology has been widely used in the logistics and distribution of fresh products because of these products' high shelf life and freshness requirements. This breaks the limitations of geographical location factors, so that consumers in various regions can 
buy better fresh products. Meanwhile, the last-mile delivery service is a key link for fresh food e-commerce companies to conduct effective management and directly contact customers in order to improve customer satisfaction and obtain benefits for the company. The last-mile delivery stage accounts for approximately $70 \%$ of the total cost of e-commerce logistics, and the delivery of packages to the door is still the most popular delivery method among consumers [2,3].

Fresh food e-commerce provides various benefits for fresh enterprises and consumers, but the development of fresh food e-commerce still has many problems and deficiencies. To this end, many scholars have also conducted active research concentrated on logistics models, logistics systems, supply chain management strategies, logistics development status, and strategies [4-6], as well as customer purchase intention and decision-making behavior $[7,8]$. Furthermore, part of the research is from the perspective of fresh food e-commerce companies, regarding the improvement of the technical level in order to meet customer service needs [9].

With fresh food e-commerce as the background, the research on the relationship between consumer satisfaction and the perceived importance of last-mile logistics services needs to be further expanded. Furthermore, related studies on the quality of fresh food e-commerce logistics services require further in-depth research and discussion from the perspective of consumers. Therefore, this study aims to establish a logistics service quality evaluation system in line with fresh food e-commerce, and to determine the quality factors that improve customer satisfaction with fresh food e-commerce logistics services. In addition, in the construction of the quality factors, the specific evaluation items which customers value are accurately determined, but the actual performance evaluation is not good. Thus, the quality factors which fresh food e-commerce enterprises need to value in logistics services are explored. Simultaneously, this study verifies the moderating effect of the consumer's perceived importance of the last-mile logistics service and its influence on the customer satisfaction of fresh food e-commerce logistics services. This study will enrich and supplement the empirical research in the field of fresh food e-commerce logistic, and will provide academic literature with a reference value for fresh food e-commerce logistics enterprises.

The rest of the paper is structured as follows. Section 2 presents the literature review, in which the quality evaluation system of the fresh food e-commerce logistics service used in this study is determined and the research hypotheses are set. Section 3 describes the questionnaire design and data collection, as well as the respondents' information and the analysis methods used. Section 4 presents the results and discussion. Using the survey data analyzed through structural equation modeling (SEM), hierarchical regression analysis, and the importance-performance analysis (I-PA) method, the path model and research hypothesis of this research are analyzed and verified. Section 5 concludes the paper, proposes suggestions, and explains the research limitations.

\section{Literature Review}

\subsection{E-Commerce Last-Mile Logistics}

The last-mile logistics of e-commerce running in the urban logistics system must be understood in the context of the urban logistics framework [10]. The increase in demand for rapid economic and e-commerce development have further increased the social and environmental negative externalities of the urban logistics system [11,12]. Among them, the last-mile logistics distribution of items within the city has become a particularly critical issue in the overall logistics development of the city [10]. At present, research on the last-mile logistics services in e-commerce focuses on the following: (1) changes in consumer habits and behavior led by last-mile delivery and aspects that impact the urban public environment, and residents' health and quality of life; (2) the cost of the urban freight distribution system and the potential optimization aspects to make it more effective; and (3) research on the impact of last-mile logistics on the development of technology applications in cities [13]. 
In last-mile logistics distribution, additional repeated distribution is required due to the emergence of 'failed deliveries' and other problems. This causes more traffic congestion, noise, pollution, and cost overruns for the logistics company. The common solution is to use lockers or self-service pickup point systems. In related studies, scholars have found that security, location, and traceability are key factors when planning a picking point network [14-16]. This has impacted the habits and behavior of consumers. The urban public environment, and residents' health and quality of life are also impacted (i.e., reducing the number of vehicles, noise, and pollution, lowering price costs, and improving the reliability and efficiency of freight). Some scholars have analyzed public sector initiatives that may be used to improve urban freight activities, such as infrastructure management, parking/loading area management, vehicle-related strategies, and traffic management [17]. Other scholars have proposed the implementation of a freight bicycle delivery system, or the use of public (subway) transportation's excess capacity to deliver documents and parcels in order to reduce the negative externalities of the last-mile logistics [18-20]. Moreover, some scholars have proposed the use of crowd logistics to implement last-mile delivery services in the context of mass social transportation [21-23].

For the research on cost and efficiency optimization related to the logistics distribution system, some researchers have proposed an optimization algorithm for a 'center to twolevel' radial logistics distribution system based on intermediate distribution points [20,24]. Moreover, some scholars have analyzed the improvement in the proportion of truck parking spaces in certain areas $[25,26]$, and the addition of a delivery system for customers picking up goods [14,27].

Meanwhile, the impact of last-mile logistics on applied technology in cities mainly involves implementing specific technologies or the specific implementation of a certain product, process, and service innovations. For instance, Yuen et al. [14] have proposed the use of smart lockers or crowd logistics services. Moreover, several researchers have proposed the following in conducting process innovations: the application of new technologies (such as real-time data collection technology, GPS systems and related navigation equipment, and the Internet of Things) and logistics technology, skills, and other urban applications in the city [17]. Furthermore, the new traffic management system (TMS) has impact on travel time and route decisions [28]. Some studies also focused on the use of digital platforms to make disruptive technologies play a positive role in the logistics industry [29].

\subsection{Fresh Food E-Commerce Logistics Services Quality Evaluation Factors}

The quality of logistics services in fresh food e-commerce is a key factor for product marketing and maintaining market competitiveness, and it is closely related to customers. Hence, the customer's purchase evaluation determines how much they value the quality of the logistics service. Therefore, the core task of fresh food e-commerce companies is to improve the quality of logistics services based on customer satisfaction [30,31]. Simultaneously, regardless of the logistics model type (e.g., self-built, third-party, and hybrid) adopted by the fresh food e-commerce companies, they need to strictly guarantee the quality of the logistics services for fresh products in the delivery process [32].

Each customer's evaluation of logistics service quality varies; therefore, the evaluation factors that meet the quality of the fresh food e-commerce logistics service must be determined. Based on the previous literature, this study integrates the characteristics of fresh food e-commerce and establishes the evaluation system of its logistics service quality.

Scholars have conducted many studies on the evaluation system of logistics service quality. Based on the theory of total quality management (TQM), Parasuraman et al. [33] proposed the following five-dimension service quality evaluation system, which is widely recognized by the academic community in the service industry: tangibles, responsiveness, reliability, assurance, and empathy. However, the dimension of SERVQUAL model mainly focuses on the function/process aspect of service quality, whereas logistics services mainly focus on the technology/result of service quality. Whether the service provides 
the promised core benefits or results can also be understood [34]. As a result, the research on the evaluation factors of logistics service quality continues to develop. For instance, Bienstock et al. [35] developed and verified a 15-item scale based on the literature on physical distribution and logistics service quality. The scale was divided into three dimensions: timeliness, availability, and condition. Then, Mentzer et al. [36,37] conceptualized it into a broader structure, including timeliness, availability, and conditions, and additional dimensions of function/ process properties.

Subsequently, many scholars have expanded the logistics service quality evaluation system through their own research. For example, Bienstock et al. [34] combined logistics process quality (procedural, contact, information, and discrepancy handling qualities) with logistics outcome quality (timeliness, availability, condition, and order accuracy), and measured logistics service quality and expanded its service. Meanwhile, Huang et al. [30] used the five dimensions of information quality, ordering procedures, timeliness, order condition, and order discrepancy handling to build an evaluation system for logistics service quality. Lin et al. [38] divided service quality into logistics and electronic service quality. The variables applied to the evaluated service quality are nine dimensions, which include order-related dimensions such as accuracy, condition, quality, and release quantities; and process-related dimensions, such as ordering procedures, discrepancy handling, timeliness, and personnel contact.

This study combines the past literature on the logistics service quality model and the SERVQUAL model, adds the unique factors of the network platform, and integrates the characteristics of fresh food e-commerce in order to establish a logistics service quality evaluation system of fresh food e-commerce. The system consists of five dimensions, namely, personnel contact quality, delivery quality, information quality, timeliness quality, and empathy quality.

\subsection{Literature Basis and Research Hypothesis}

\subsubsection{The Effects of Fresh Food E-Commerce Logistics Service Quality on} Customer Satisfaction

Many studies have shown that service quality is an important factor affecting customer satisfaction. Dividing the logistics service quality into process quality and result quality, Bienstock et al. [34] concluded that the result quality has a direct positive impact on satisfaction. However, the process quality has an indirect impact on the satisfaction of logistics services by positively affecting the result quality. Huang et al. [30] demonstrated the positive impact of logistics service quality on consumer satisfaction. From the perspective of consumers, Lin et al. [38] determined the conceptual model and measurement scale through literature review, and then used the collected data analysis to conclude that the quality of logistics services has a positive impact on customer satisfaction. Meanwhile, Fernandes et al. [39] adopted an exploratory qualitative design and conducted in-depth interviews with five customers and five managers of a lubricant manufacturer located in Umarama, Paraná, Brazil, and nearby areas. A total of 117 companies in the Brazilian lubricant market conducted a descriptive survey. The final analysis demonstrated the positive impact of logistics service quality on customer satisfaction. Hong et al. [31] used online comment information as the research object in their study. They employed a convolutional neural network text-mining model for their analysis, and sentiment analysis to convert comment information into digital information. Finally, convenience, communication, reliability, and responsiveness in logistics service elements were found to have a significant impact on customer satisfaction, whereas integrity had none. Their results confirm the positive impact of physical distribution service quality on consumer satisfaction in online shopping. Hence, the following hypothesis is proposed:

Hypothesis 1 (H1). The logistics service quality of fresh food e-commerce has a positive effect on the customer satisfaction.

For fresh products, the quality of personnel is required due to the complex distribution requirements. In particular, the courier's attitude, timeliness, professional response ability, 
and understanding of customer needs, among others, are critical. Especially in the last-mile delivery process, they will directly contact consumers, which will directly affect the overall evaluation of logistics services. Hence, the following hypothesis is proposed:

Hypothesis 1a (H1a). The personnel contact quality in the logistics service quality of fresh food e-commerce has a positive effect on the customer satisfaction.

Compared with other general industrial products, fresh commodities have higher requirements for transportation. Customers need commodities to be delivered to designated locations on time, and the freshness of products must be ensured throughout the logistics process; otherwise, customer complaints will increase. This requires increasing the use of cold chain technology. Delivery quality indicators include cold chain technology (refrigerated trucks, etc.), the accuracy of the fresh product distribution, the freshness of the fresh products, and the cleanliness of the packaging. Hence, the following hypothesis is proposed:

Hypothesis $\mathbf{1 b} \mathbf{( H 1 b ) . ~ T h e ~ d e l i v e r y ~ q u a l i t y ~ i n ~ t h e ~ l o g i s t i c s ~ s e r v i c e ~ q u a l i t y ~ o f ~ f r e s h ~ f o o d ~ e - c o m m e r c e ~}$ has a positive effect on the customer satisfaction.

The online shopping process is always accompanied by the generation and exchange of information. Information quality includes the timeliness of query information, the difficulty of obtaining information, the timeliness and accuracy of communication and feedback information, and the accuracy of tracking and location information. In terms of logistics services, fresh food e-commerce enterprises allow consumers to accurately track information in a timely fashion, clearly inform consumers of the time and place of the delivery of fresh products, and provide a channel for customer feedback and complaints. As a result, it promotes the overall evaluation of the logistics service and the improvement of service satisfaction. Hence, the following hypothesis is proposed:

Hypothesis 1c (H1c). The information quality in the logistics service quality of fresh food ecommerce has a positive effect on customer satisfaction.

Timeliness mainly investigates whether fresh food e-commerce enterprises can respond to consumers' demands effectively, and in a timely fashion. This includes delivery time, the ability to respond to delivery requests in a timely fashion, and the merchant's ability to deliver goods and respond to return requests. Fresh food e-commerce enterprises can shorten the logistics service cycle, enhance the service speed, and quickly respond to customer's service requests in order to improve consumers' overall evaluation and the service satisfaction of logistics services. Hence, the following hypothesis is proposed:

Hypothesis 1d (H1d). The timeliness quality in the logistics service quality of fresh food ecommerce has a positive effect on customer satisfaction.

The empathy quality is embodied in whether the company and employees will stand in the perspective of customers, provide customers with personalized services, and protect customer's safety and rights. For customers who buy fresh products, they need detailed explanations and careful guidance from fresh food e-commerce because the purchase process will be different from traditional online shopping. Simultaneously, fresh products may have hidden dangers of staleness; hence, the food safety of fresh products and good return service must be ensured. Moreover, the business must guarantee transaction security and customer privacy security. All of this will promote the improvement of consumer satisfaction with logistics services. Hence, the following hypothesis is proposed:

Hypothesis 1e (H1e). The empathy quality in the logistics service quality of fresh food e-commerce has a positive effect on customer satisfaction. 
2.3.2. The Relationship between Customers' Perceived Importance of Last-Mile Logistics Services and Customer Satisfaction

The past literature has demonstrated a high correlation between perceived importance and satisfaction [40-44]. For example, Kim and Lim [40] focused on the attributes of companies with regard to consumers' online shopping, and studied the relationship between consumers' perceived importance of online shopping and satisfaction. Moreover, researchers have discovered - through data collection and analysis-a correlation between the entertainment, speed, information quality, and reliability factors of consumers' perceived importance and online shopping satisfaction. Meanwhile, Mar et al. [43] demonstrated the relationship between the perceived importance of the content of 'daydreams' and life satisfaction. That is, the closer the relationship between the characters in the 'daydream' and themselves, the stronger the perceived importance of the relationship, and the higher the life satisfaction. Wolfram and Gratton [44] demonstrated that the perceived importance of roles has a positive effect on subjective health and life satisfaction.

Hypothesis 2 (H2). The perceived importance of last-mile logistics service has a positive effect on customer satisfaction.

Consumers with similar use values will moderate their satisfaction with the service according to their perception of the importance of a certain part [45]. In addition, the perceived level of importance of the chosen service level will vary depending on the values of the user. If consumers choose service options that they perceive to be more important when choosing services, then the consumers' satisfaction with their use will be improved [46]. Therefore, this study argues that if consumers realize the use of any dimension of the service from the perspective of perceived importance, it will have a more positive moderating influence on usage satisfaction.

The moderating effect of perceived importance has been verified in previous studies. For example, Amorose and Nolan-Sellers [47] explored whether athletes' emphasis on coaching behavior will regulate the relationship between athletes' perceptions of coaches' feedback and their own ability. Meanwhile, previous studies have confirmed that perceived importance not only directly affects satisfaction but also has a moderating effect on satisfaction [44-46,48]. Kim [45] found that, in the evaluation of consumer services in water parks, consumers with a higher perceived importance of safety have a higher service satisfaction than other consumers. Jeong [46] revealed the importance of service users' attention in choosing between two factors and the relationship between these two factors on user satisfaction. The results showed that, in the relationship between the choice of these two factors and satisfaction, the moderating effect of perceived importance is significant. Iseke [48] and Wolfram and Gratton [44] both found that the individual's perception of role importance positively regulates individual satisfaction. Iseke [48] proposed that the personal perception of the importance of family roles has a significant and positive effect on the relationship between part-time employees and job satisfaction. In part-time work, employees' high attention to family roles can improve their job satisfaction. Wolfram and Gratton [44] proposed that individuals' perceptions of the importance of family roles play a positive and significant moderating role in life satisfaction. Hence, the following hypothesis is proposed:

Hypothesis 3 (H3). The perceived importance of customers regarding the last-mile logistics service has a moderating effect on the impact between the evaluation factors of fresh food e-commerce logistics service quality and customer satisfaction.

Figure 1 illustrates the relationships between the identified dimensions. 


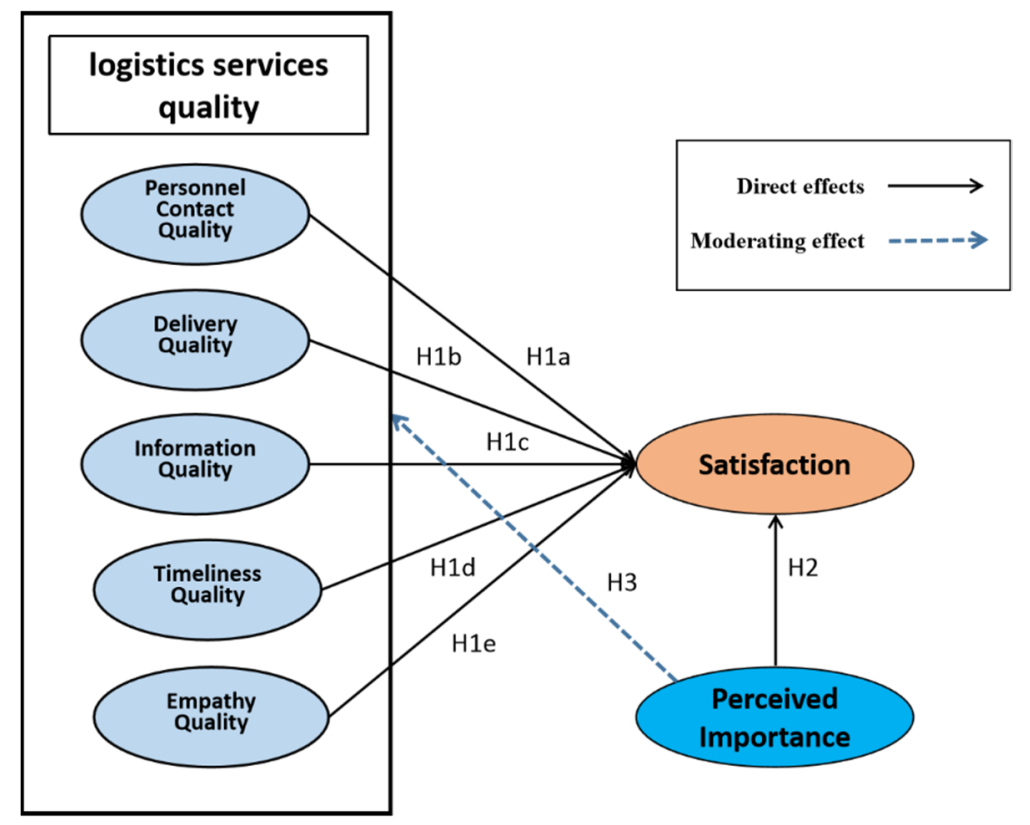

Figure 1. Research framework and the path model for the hypothesis.

\section{Methodology}

\subsection{Questionnaire Design and Measures}

The measurement table of this research is adopted from the past research literature and existing projects. The first-level constructs used are personnel contact quality, delivery quality, information quality, timeliness quality, empathy quality, and consumers' satisfaction and perceived importance of the last-mile logistics service. Each first-level factor includes multiple second-level items. Table 1 shows the constructs, measurement items, and related references used to develop the measurement table. The survey uses a 5-point Likert scale ranging from $1=$ disagree strongly (very dissatisfied) to $5=$ agree strongly (very satisfied).

Table 1. Constructs and measurement items.

\begin{tabular}{|c|c|c|}
\hline Construct & Item & Source \\
\hline $\begin{array}{c}\text { Personnel Contact } \\
\text { Quality (PCQ) }\end{array}$ & $\begin{array}{l}\text { PCQ1: Fresh food e-commerce logistics courier has a good service attitude and behavior } \\
\text { PCQ2: Fresh food e-commerce logistics courier will patiently and kindly answer the } \\
\text { customer's inquiry } \\
\text { PCQ3: Fresh food e-commerce logistics couriers understand my service needs } \\
\text { PCQ4: Fresh food e-commerce logistics couriers have a sense of responsibility, will think } \\
\text { for customers, have good business ability } \\
\text { PCQ5: The courier service attitude of fresh food e-commerce logistics is not excellent* }\end{array}$ & [49] \\
\hline $\begin{array}{l}\text { Delivery Quality } \\
\text { (DLQ) }\end{array}$ & $\begin{array}{l}\text { DLQ1: The fresh products I buy are distributed by cold chain logistics (such as } \\
\text { refrigerated trucks and cold chain trucks.) } \\
\text { DLQ2: The fresh products I buy will be delivered to the customer's designated place on } \\
\text { time and accurately } \\
\text { DLQ3: The fresh products I buy can guarantee freshness and product quality during the } \\
\text { delivery process } \\
\text { DLQ4: The fresh products I buy has package intact and are clean during the } \\
\text { delivery process }\end{array}$ & [31] \\
\hline
\end{tabular}

IMQ1: After I buy fresh products, I can timely and accurately query the logistics distribution information

Information Quality IMQ2: After I buy fresh products, I can easily query the logistics distribution information (IMQ)

IMQ3: After I buy fresh products, I can get complete and sufficient feedback on logistics distribution information

IMQ4: After I buy fresh products, I can get complete and sufficient feedback on logistics distribution information 
Table 1. Cont

\begin{tabular}{|c|c|c|}
\hline Construct & Item & Source \\
\hline $\begin{array}{l}\text { Timeliness Quality } \\
\text { (TLQ) }\end{array}$ & $\begin{array}{l}\text { TLQ1: After I purchased fresh products, the logistics service provider took a short time } \\
\text { from the package to the final delivery of the product } \\
\text { TLQ2: After I buy fresh products, the logistics service provider can deliver goods quickly } \\
\text { TLQ3: After I buy fresh products, the time for pending orders at the logistics level is short } \\
\text { TLQ4: After I purchase fresh products, if the products are not delivered on time, the } \\
\text { logistics service provider will quickly arrange delivery }\end{array}$ & {$[30,36,49,51]$} \\
\hline $\begin{array}{c}\text { Empathy Quality } \\
\text { (EPQ) }\end{array}$ & $\begin{array}{l}\text { EPQ1: When I use fresh logistics services, I feel I have gained a gratifying sense of security } \\
\text { EPQ2: When I had problems using the fresh logistics service, logistics service providers } \\
\text { will give me sympathy and comfort, and provided good return service when necessary } \\
\text { EPQ3: When I had problems using the fresh logistics service, logistics service providers } \\
\text { will put themselves in a position to solve problems for me } \\
\text { EPQ4: When I had problems using the fresh logistics service, they paid special attention } \\
\text { EPQ5: When I had problems using the fresh logistics service, I will get full help and } \\
\text { support; they will protect my personal information privacy }\end{array}$ & [33] \\
\hline $\begin{array}{c}\text { Perceived } \\
\text { Importance }(\mathrm{PI})\end{array}$ & $\begin{array}{l}\text { PI1: In the last-mile logistics service process, I think it is important to provide detailed } \\
\text { delivery information and to communicate with the customer about the details of } \\
\text { the delivery. } \\
\text { PI2: In the last-mile logistics service process, I think the delivery location should be safe } \\
\text { and reliable, and the protection of personal information security is important. } \\
\text { PI3: In the last-mile logistics service process, I think that the options for customers to pick } \\
\text { up the goods conveniently and easily, and enjoy various services easily are important } \\
\text { PI4: In the last-mile logistics service process, I think the speed of delivering goods and the } \\
\text { timeliness of retrieval of delivery information are important }\end{array}$ & {$[40]$} \\
\hline Satisfaction (SAT) & $\begin{array}{l}\text { SAT1: What is your overall evaluation of the fresh food e-commerce logistics service? } \\
\text { SAT2: How do you feel about the service experience of fresh food e-commerce logistics? } \\
\text { SAT3: How do you feel about the customer service of fresh food e-commerce logistics? } \\
\text { SAT4: How do you feel about the last-mile logistics service of fresh food } \\
\text { e-commerce logistics? } \\
\text { SAT5: How do you feel about the delivery information provision service of fresh food } \\
\text { e-commerce logistics? }\end{array}$ & {$[49,52]$} \\
\hline
\end{tabular}

Note: * PCQ5 is a reverse-scaled item used to access the quality of the survey responses.

In addition, in order to determine which quality factors should be the focus of fresh food e-commerce companies in the last-mile logistics services, this study uses an I-PA analysis method to screen out the factors emphasized by customers which do not perform well [42]. The specific content of the survey questions was determined by modifying each question of Personnel Contact Quality (PCQ), Delivery Quality (DLQ), Information Quality (IMQ), Timeliness Quality (TLQ), and Empathy Quality (EPQ) in Table 1. The survey used a 5-point Likert scale to measure the importance and performance (customer satisfaction) of each secondary indicator: $1=$ very unimportant/very dissatisfied, $2=$ unimportant/unsatisfied, $3=$ general, $4=$ important $/$ satisfied, $5=$ very important/very satisfied .

\subsection{Survey Design and Administration}

This research is mainly focused on Chinese fresh food e-commerce; in this case, the survey was targeted at Chinese Internet consumers. In order to ensure the accuracy of the expression of the questionnaire, the questionnaire was first translated from English into Chinese, and then back-translated from Chinese into English. Before the formal questionnaire survey, a pre-test was conducted with eight participants in order to verify the readability of the questionnaire. Finally, the questionnaire was revised based on the results of the comparison and the feedback from the interviewees.

The survey was conducted for two rounds: the first round was applied between 1 November and 10 November 2020. A QR code was generated and distributed at the main supermarket that provided the fresh food online shopping services. A representative was stationed at the entrance of the supermarket once every fortnight to approach passersby at 
random. Thereafter, they were invited to complete the online survey questionnaire. The second round was conducted online via the survey platform by sending out invitations randomly between 1 December and 10 December. A total of 273 completed survey questionnaires were collected. According to previous studies, if the sample size is greater than 200, the stability of the SEM study will not be affected [53]. Therefore, the sample size of this research is suitable for SEM research.

\subsection{Analytical Method}

Importance-Performance Analysis (IPA) is usually used to distinguish the difference between the important factor of a problem that consumers value and the actual management behavior of the service provider on the problem [42]. IPA analysis illustrates the average importance and performance results of the four quadrants of characteristics, distinguishes the gap between consumers' awareness of the importance of specific logistics service quality factors and the performance of the company that provides logistics services in the actual management of quality factors, and determines the domain of the resources which require redistribution. In this case, it can help to improve the quality of the logistics service [42,54]. The four quadrants in IPA are: First of all, where the customer perceives the company's performance (or service quality) to be good, i.e., "keep up the good work"; Secondly, the customer attaches great importance to the second quadrant, in which the company's performance is poor and needs to focus on improvement, e.g., "concentrate here"; The third quadrant is resource allocation decisions, e.g., "low priority"; and the fourth quadrant is relatively less important, in which companies over-allocate resources to these attributes, i.e., "probable overkill" [54].

Structural equation modeling (SEM) is one of the most commonly used analytical methods in social sciences such as international business and marketing. SEM includes measurement equations, structural equations, factor analysis, path analysis and regression, which can be simply understood as a combination of factor analysis, and multiple regression modelling [55]. The factor analysis is used to assess the appropriateness of the variables used in the model, and multiple regression is used to estimate the hypothesized effects of some variables on others [56]. The most significant advantage of SEM is the ability to simultaneously model and display the indirect and direct influence of the relationships that exist between multiple dependent and independent variables [56]. SEM is particularly useful for the analysis of data collected by methods such as surveys and experiments, and for evaluating the validity, reliability, and predictability of structural measurement scales ([55]. In addition, SEM can handle more complex model structures (such as non-normality and multicollinearity, etc.) $[55,56]$. Therefore, SEM can meet the needs of this study to measure and estimate the influence of the relationships in the path model.

\subsection{Respondent Demographics}

For the demographic characteristics of the respondents. In terms of age distribution, $45.1 \%$ (123 people) of the respondents were aged 30 to 40 , and $28.6 \%$ of respondents were aged 20 to 30, 30 to 40, respectively, (78 people), and 40 to 50, were $19.4 \%$ (53 people). The remaining respondents, who were under 20 and over 50 , accounted for $4.0 \%$ (11 people) and $2.9 \%$ (8 people), respectively. Their occupational situation was that sales and service personal (e.g., driver/waiter) and freelancers (e.g., writer/artist/photographer) accounted for the largest proportion. In terms of monthly income, $40 \%$ of the respondents had between $\$ 4000$ and $\$ 6000$ income. Simultaneously, $69.6 \%$ of the respondents obtained a college degree or above post-secondary education, and $70.2 \%$ of them lived in provincial capitals or Shenzhen, Qingdao, Dalian, Suzhou (urban areas) and prefecture level cities (urban areas). 


\section{Results of the Empirical Analysis}

\subsection{Measurement Model Analysis}

In order to assess the overall model, fit, reliability, and validity of the measures, a confirmatory factor analysis was conducted. The fit indices of the measurement model, standardized factor loadings ( $\lambda$ ), average variance extracted (AVE), and composite reliability (CR) of the constructs are presented in Table 2. The measurement items with factor loadings less than 0.70 were removed.

Table 2. Confirmatory factor analysis results.

\begin{tabular}{|c|c|c|c|c|}
\hline Construct & Item & $\lambda$ & AVE & CR \\
\hline \multirow{3}{*}{ Personnel contact quality (PCQ) } & PCQ1 & 0.79 & 0.66 & 0.85 \\
\hline & PCQ2 & 0.79 & & \\
\hline & PCQ4 & 0.85 & & \\
\hline \multirow{4}{*}{ Information quality (IMQ) } & IMQ1 & 0.79 & 0.64 & 0.88 \\
\hline & IMQ2 & 0.80 & & \\
\hline & IMQ3 & 0.81 & & \\
\hline & IMQ4 & 0.81 & & \\
\hline \multirow{4}{*}{ Empathy quality (EPQ) } & EPQ2 & 0.76 & 0.62 & 0.87 \\
\hline & EPQ3 & 0.74 & & \\
\hline & EPQ4 & 0.81 & & \\
\hline & EPQ5 & 0.84 & & \\
\hline \multirow{3}{*}{ Satisfaction (SAT) } & SAT1 & 0.75 & 0.63 & 0.84 \\
\hline & SAT3 & 0.83 & & \\
\hline & SAT4 & 0.81 & & \\
\hline \multirow{4}{*}{ Delivery quality (DLQ) } & DLQ1 & 0.88 & 0.76 & 0.93 \\
\hline & DLQ3 & 0.88 & & \\
\hline & DLQ2 & 0.89 & & \\
\hline & DLQ4 & 0.84 & & \\
\hline \multirow{4}{*}{ Timeliness quality (TLQ) } & TLQ1 & 0.80 & 0.65 & 0.88 \\
\hline & TLQ2 & 0.81 & & \\
\hline & TLQ3 & 0.85 & & \\
\hline & TLQ4 & 0.75 & & \\
\hline \multirow{4}{*}{ Perceived importance (PI) } & PI1 & 0.79 & 0.68 & 0.90 \\
\hline & PI2 & 0.80 & & \\
\hline & PI3 & 0.84 & & \\
\hline & PI4 & 0.87 & & \\
\hline
\end{tabular}

Note: Model fit indices: $\chi^{2}=559.870 ; \chi^{2} / \mathrm{df}=2.014,(p<0.05, \mathrm{df}=278) ; \mathrm{CFI}=0.94 ; \mathrm{TLI}=0.93 ; \mathrm{RMSEA}=0.061 ;$ SRMR $=0.0566$.

The fit indices are shown in the notes of Table 2. The results show that the comparative fit index (CFI), Tucker-Lewis fit index (TLI), root mean square error of approximation (RMSEA), and standardized root mean square residual (SRMR) met the cut-off criteria proposed by [57]. The following values were obtained in this study: CFI and TLI $>0.90$, RMSEA $<0.08$, and SRMR $<0.10$. These results show that the measurement model has a good fit.

Furthermore, the standardized factor loadings representing the correlation between the measure and its construct, as well as the CRs of the constructs, were inspected in order to determine the reliability of the measures. Table 2 shows that the CRs of the standardized factor load and structure are higher than the recommended thresholds of 0.70 and 0.80 , respectively [58], indicating the reliability of the measurement tools.

The validity of the measurement tool was evaluated using convergent and discriminant validity. The values in the main diagonal of Table 3 represent the AVE of each construct, and are above the recommended criteria of 0.50 , indicating convergent validity [59]. The values below the main diagonal and above the main diagonal show the correlation and squared correlation of the constructs. Moreover, Table 3 shows that the 
AVE of each construct is always greater than its squared correlation with other constructs. Therefore, these constructs are different from each other and support discriminant validity.

Based on the above results, the measurement model has a good fit, and its related measurement items are effective and reliable. Therefore, this study can formally test its hypotheses.

Table 3. AVE, correlations, and squared correlations of the constructs.

\begin{tabular}{cccccccc}
\hline & SAT & PI & EPQ & TLQ & IMQ & DLQ & PCQ \\
\hline SAT & $\mathbf{0 . 6 3}^{\mathbf{a}}$ & $\mathbf{0 . 2 6} \mathbf{6}^{\mathbf{c}}$ & 0.25 & 0.27 & 0.27 & 0.04 & 0.35 \\
PI & $\mathbf{0 . 5 1}^{\mathbf{b}}$ & $\mathbf{0 . 6 8}$ & 0.06 & 0.47 & 0.09 & 0.27 & 0.05 \\
EPQ & 0.50 & 0.25 & $\mathbf{0 . 6 2}$ & 0.04 & 0.39 & 0.00 & 0.36 \\
TLQ & 0.52 & 0.68 & 0.21 & $\mathbf{0 . 6 5}$ & 0.05 & 0.08 & 0.11 \\
IMQ & 0.52 & 0.30 & 0.62 & 0.22 & $\mathbf{0 . 6 4}$ & 0.03 & 0.47 \\
DLQ & 0.21 & 0.52 & 0.02 & 0.29 & 0.17 & $\mathbf{0 . 7 6}$ & 0.00 \\
PCQ & 0.59 & 0.23 & 0.60 & 0.33 & 0.69 & -0.02 & $\mathbf{0 . 6 6}$ \\
\hline
\end{tabular}

Note: ${ }^{\mathrm{a}}$ AVE values are along the main diagonal. ${ }^{\mathrm{b}}$ The correlations between the constructs are below the main diagonal. ${ }^{\mathrm{c}}$ The squared correlations between the constructs are above the main diagonal.

\subsection{Structural Model Analysis}

Figure 2 shows the estimated structural parameters in the direct effects model. The control variables - namely, gender and age-are added to the model to rationalize the impact of fresh food e-commerce logistics service quality on the consumer satisfaction of fresh food e-commerce logistics service.

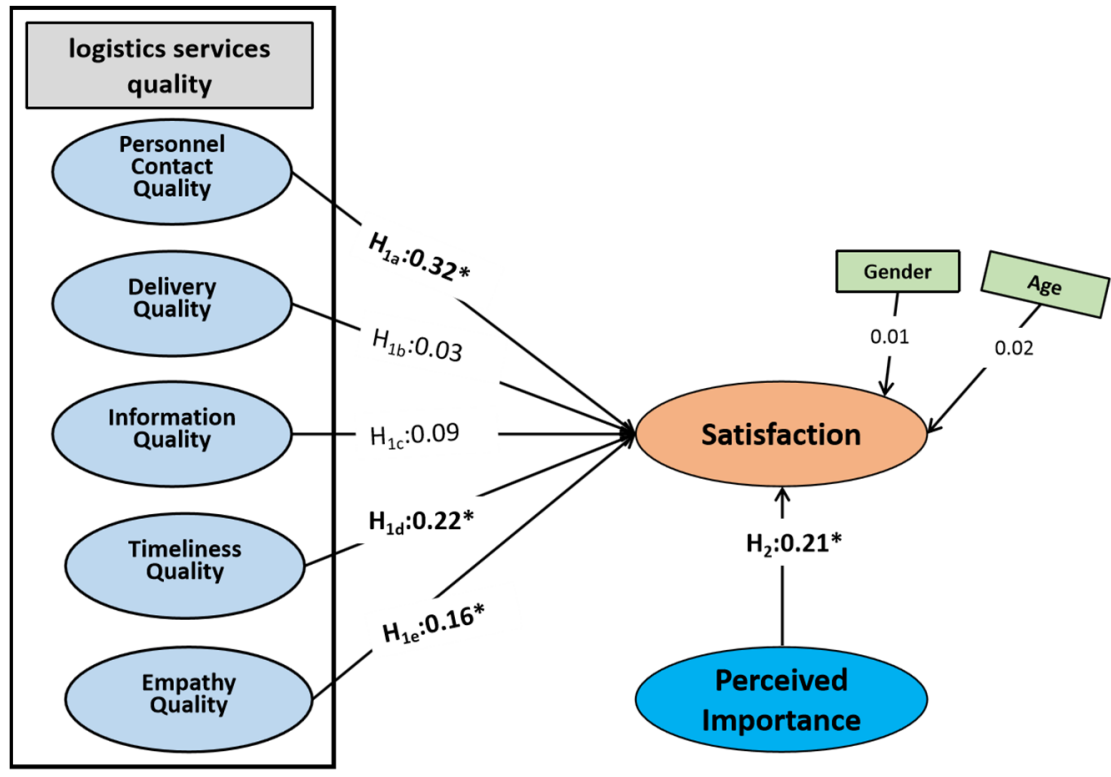

Figure 2. Parameter estimation for the SEM analysis of the hypothesis testing. ${ }^{*}$ indicates that the path estimate is significant $(p<0.05)$.

Figure 2 shows that the structural model has a good fit $\left({ }^{*}\right.$ indicates that the path estimate is significant $p<0.05 ; \chi^{2} / \mathrm{df}=1.842 ; \mathrm{CFI}=0.94 ; \mathrm{TLI}=0.93$; $\mathrm{RMSEA}=0.056$; SRMR $=0.056)$. The multiple squared correlation $\left(R^{2}=0.54\right)$ of the quality of fresh food ecommerce logistics services with the perceived importance of the last-mile logistics services of fresh food e-commerce and consumer satisfaction with the logistics services of fresh food e-commerce is greater than 0.5 . This fully demonstrates the explanatory power of the relevant exogenous variables.

Among the five construction factors of the model, personnel contact quality, timeliness quality, and empathy quality have a significant positive impact on the consumer satisfaction of fresh food e-commerce logistics services. The standardized estimation coefficients are 
$0.32,0.22$, and 0.16 , respectively (all $p$ values $<0.05$ ). This indicates that $\mathrm{H} 1 \mathrm{a}, \mathrm{H} 1 \mathrm{~d}$, and H1e should be accepted. However, the impact of delivery quality and information quality on consumer satisfaction is not significant ( $p$ value greater than 0.05 ), and we should thus reject $\mathrm{H} 1 \mathrm{~b}$ and $\mathrm{H} 1 \mathrm{c}$. In addition, consumers' perceived importance of last-mile logistics services has a positive and significant impact on the consumer satisfaction of fresh food e-commerce logistics services, with a standardized estimated coefficient of 0.21 ( $p$ value greater than 0.05), and thus $\mathrm{H} 2$ should be accepted.

As shown in Figure 2, the fresh food e-commerce logistics service quality evaluation system and consumers' perceived importance of the last-mile flow service explained 54\% of the variance in consumer satisfaction $\left(R^{2}=0.54\right)$. Although the result is different from the expected existence, the relevant results have demonstrated the research model of fresh food e-commerce logistics services.

\subsection{Verification Analysis of the Moderating Effect}

From the previous section, the personnel contact, timeliness, and empathy qualities in the five quality evaluation dimensions have a significant positive impact on consumer satisfaction. The other two dimensions, delivery quality and information quality, did not have a significant impact on consumer satisfaction. Therefore, this section verifies whether the impact of these five evaluation dimensions on the consumer satisfaction is impacted by the moderating effect of consumers on the perceived importance of last-mile logistics services in order to demonstrate whether hypothesis $\mathrm{H} 3$ is valid.

This study will use hierarchical regression analysis to verify the consumers' moderating effect on the last-mile logistics service's perceived importance. Table 4 shows the results of the use of hierarchical regression analysis. In order to avoid the existence of collinearity problems, this study conducted mean centralization processing for the independent and moderating variables. Afterward, the new variables processed by mean centering were used to calculate the interaction terms between the moderating variable and each independent variable.

Table 4. Hierarchical regression analysis to validate the moderating effect.

\begin{tabular}{|c|c|c|c|}
\hline Variables (i) & $\begin{array}{c}\text { Step } 1 \\
\text { bi }\end{array}$ & $\begin{array}{c}\text { Step } 2 \\
\text { bi }\end{array}$ & $\begin{array}{c}\text { Step } \\
\text { bi }\end{array}$ \\
\hline Constant & $3.31 * * *$ & $3.34 * * *$ & $3.26 * * *$ \\
\hline Gender & 0.06 & 0.06 & 0.06 \\
\hline Age & 0.03 & 0.03 & 0.02 \\
\hline Education & $-0.07^{* *}$ & $-0.07^{* *}$ & $-0.07 * *$ \\
\hline Job & -0.02 & -0.02 & -0.02 \\
\hline Income & $0.09 * * *$ & $0.09 * * *$ & $0.11 * * *$ \\
\hline Residential area & 0.01 & 0.02 & 0.03 \\
\hline Personnel Contact Quality & $0.39 * * *$ & $0.39 * * *$ & $0.37 * * *$ \\
\hline Delivery Quality & 0.03 & 0.02 & 0.04 \\
\hline Information Quality & $0.16 * * *$ & $0.16 * * *$ & 0.00 \\
\hline Timeliness Quality & $0.14 * * *$ & $0.13 * * *$ & $0.21 * * *$ \\
\hline Empathy Quality & $0.11 * *$ & $0.11 * * *$ & $0.25 * * *$ \\
\hline Perceived Importance & & 0.03 & 0.03 \\
\hline$P C Q \times P I$ & & & -0.01 \\
\hline $\mathrm{DLQ} \times \mathrm{PI}$ & & & 0.05 \\
\hline $\mathrm{IMQ} \times \mathrm{PI}$ & & & $-0.14 * *$ \\
\hline $\mathrm{TLQ} \times \mathbf{Q} \times \mathbf{P I}$ & & & $0.08 *$ \\
\hline $\mathrm{EPQ} \times \mathbf{P I}$ & & & $0.15 * *$ \\
\hline $\mathbf{R}^{2}$ & 0.514 & 0.514 & 0.541 \\
\hline$\Delta \mathrm{R}^{2}$ & 0.514 & 0.001 & 0.027 \\
\hline$\Delta \mathbf{F}$ & $25.066 * * *$ & 0.369 & $3.011 * *$ \\
\hline
\end{tabular}


First, this study applies demographic information, such as 'gender,' 'age,' 'education,' 'job,' 'income,' and 'residential area', to the regression model in Step 1. Simultaneously, the independent variables-namely, personnel contact, delivery, information, timeliness, and empathy qualities processed using centralization-are also added to the regression model of Step 1. Through the analysis, the R-square in step 1 was determined to be 0.514 , and the amount of change in R-square $\left(\triangle \mathrm{R}^{2}\right)$ was $0.514(\triangle \mathrm{F}=25.066, p<0.01)$. In addition, the following values were obtained: the constant in the model $(=3.31, p<0.01)$, and the variables in education $(\mathrm{bi}=-0.07, p<0.05)$, income $(\mathrm{bi}=0.09, p<0.01)$, personnel contact quality ( $\mathrm{bi}=0.39, p<0.01)$, information quality ( $\mathrm{bi}=0.16, p<0.01)$, timeliness quality ( $\mathrm{bi}=0.14, p<0.01)$, and empathy quality ( $\mathrm{bi}=0.11, p<0.05)$. These have a significant influence on the dependent variable.

In Step 2, this study adds a regression model after the mean centralization of the moderating variable, perceived importance, in the Step 1. Through the analysis, the $R$-squared was 0.514 in Step 2, and the amount of change in the R-square $\left(\Delta R^{2}\right)$ was almost $0(\Delta \mathrm{F}=0.369, p>0.1)$. Simultaneously, the coefficients of the variables did not change significantly. This means that after adding the moderating variable-perceived importance- to the regression model, it did not have a significant effect.

In order to further verify the moderating effect on the Step 2, the means-centered processing of the moderating variable is applied. The analysis showed that the R-squared was 0.541 in Step 3, and the amount of change in the R-squared $\left(\Delta R^{2}\right)$ was $0.027(\Delta F=3.011$, $p<0.05$ ). Simultaneously, the coefficients of various variables changed significantly. However, the moderating variable-perceived importance-still does not have a significant effect on the dependent variable. In addition, among the interaction terms added to the model, only IMQ $\times$ PI $(\mathrm{bi}=-0.14, p<0.05), \mathrm{TLQ} \times \mathrm{PI}(\mathrm{bi}=0.08, p<0.1)$, and $\mathrm{EPQ} \times \mathrm{PI}$ (bi $=0.15, p<0.05)$ had a significant effect on the dependent variable. Hence, the moderating effect of perceived importance is partially present in Step 3, but it has limitations. Therefore, $\mathrm{H} 3$ should not be fully accepted.

\subsection{Importance-Performance Analysis}

This research aims to understand the factors that customers value the most, but which do not perform well in the last-mile logistics service of fresh commodities. An I-PA method was used to analyze and determine the key factors.

According to the I-PA quadrant distribution (Figure 3), 10 indicators are in the first quadrant ("keep up the good work"), which accounts for the most indicators, whereas five indicators in the second quadrant ("concentrate here"), four indicators are in the third quadrant ("low priority"), and two indicators are in the fourth quadrant ("possible overkill").

According to Figure 3, fresh food e-commerce must focus on logistics quality items in the second quadrant. Therefore, fresh food e-commerce should change the allocation of resources from quadrant 4 to quadrant 2. That is, the IMQ1, IMQ2, TLQ1, EPQ2, and EPQ5 shown in the Figure 3 need to be improved. They respectively belong to information quality evaluation dimensions (IMQ1, IMQ2), timeliness quality evaluation dimensions (TLQ1), and empathy quality evaluation dimensions (EPQ2, EPQ5).

Based on the above content, this study can be further determined. First, fresh food e-commerce companies can expand the channels for information release and make rational use of various social platforms so that consumers can more easily inquire about logistics and distribution information in a timely fashion. Second, fresh food e-commerce companies must still further shorten the delivery cycle of goods, so that consumers can maximize the time from placing an order to purchase products to the final receipt. Because of the special attributes of fresh products, they are prone to quality and safety hazards such as corruption and deterioration. When consumers request returns because of freshness or quality and safety issues, for example, fresh food e-commerce companies should respond more promptly in order to ensure the speed and smoothness of the service process. Finally, in the information age, we all need more empathy, putting ourselves on the ground to protect consumers' privacy and prevent information leakage. Especially in the entire 
transaction and product delivery process, consumers' property safety, personal and family members' information and privacy safety, and so on need to be properly protected.

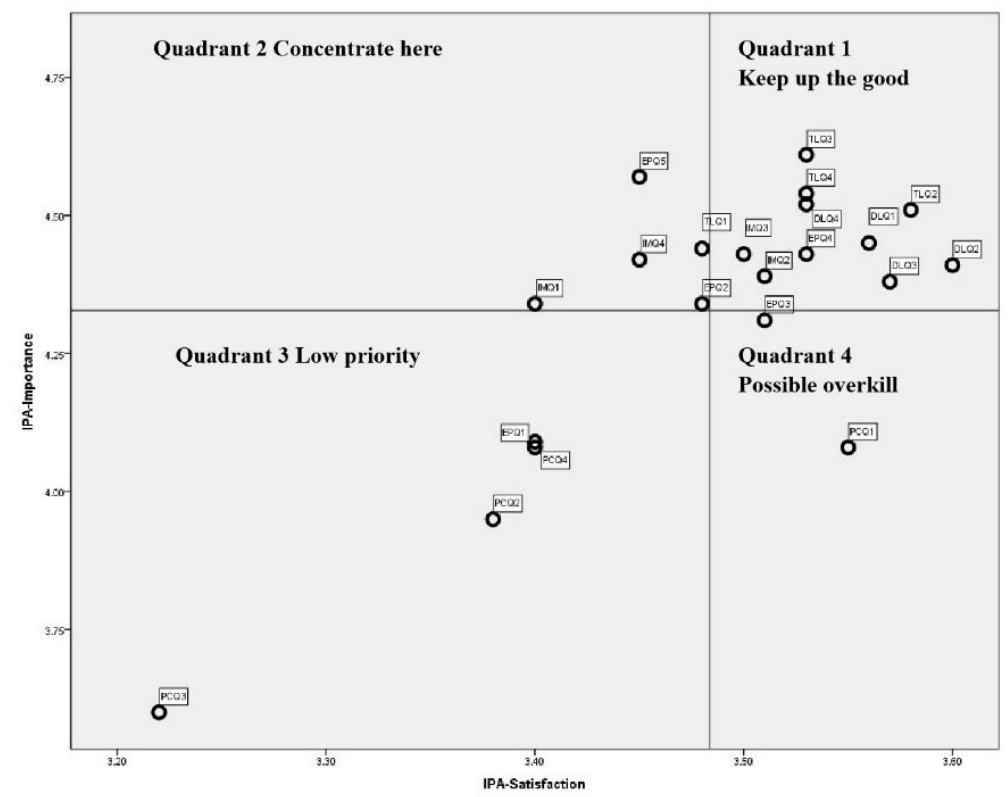

Figure 3. I-PA analysis of the importance and satisfaction of the quality factors.

\section{Conclusions and Discussion}

\subsection{Results Summary and Discussion}

This study determines the quality factors of fresh food e-commerce logistics services that can further improve customer satisfaction. In addition, this study verifies the relationship between the customer's perceived importance of the last-mile logistics service and the customer satisfaction, as well as its moderating effect on the relationship between the quality and customer satisfaction of fresh food e-commerce logistics. Simultaneously, this paper analyzes and determines the key factors in the last-mile logistics service of fresh goods that customers value most. However, the actual performance evaluation is unsatisfactory. The analysis results of this study are as follows.

Firstly, the influence relationship between the logistics service quality of fresh food e-commerce and the customer satisfaction was verified. Among them, the personal contact quality, timeliness quality, and empathy quality in the logistics service quality of fresh food e-commerce have a significant positive impact on the consumer satisfaction. However, the other two factors - namely, delivery quality and information quality - have no significant impact on consumer satisfaction. Therefore, hypotheses H1a, H1d, and H1e of this study are accepted, whereas hypotheses $\mathrm{H} 1 \mathrm{~b}$ and $\mathrm{H} 1 \mathrm{c}$ are rejected.

Several variables with significant effects are worth discussing. First, personnel contact quality has a positive impact on the consumer satisfaction of fresh food e-commerce logistics services. This is consistent with the research viewpoint put forward by Bienstock et al. [34]. Fresh products are different from other online shopping products. Their special characteristics lead to more complicated distribution and higher requirements for the quality of the distribution personnel. In particular, the courier's attitude and ability to respond to emergencies, professional skills in delivering fresh products, and understanding of customer needs are critical. In addition, during the last-mile delivery, couriers contact consumers directly. Therefore, improving the personal contact quality will enhance the consumer satisfaction of fresh food e-commerce logistics services. Second, timeliness quality has a positive impact on the consumer satisfaction of fresh food e-commerce logistics services. This result is supported by the viewpoint put forward by Lin et al. [38]. Because the consumers look for fresh products' freshness, the quality requirements are higher, and the product preservation period itself is shorter. Therefore, consumers will 
have higher requirements for delivery time, the merchant's delivery capacity, and the merchant's response to the consumer's return request. Fresh food e-commerce can improve the timeliness service quality by increasing transportation capacity, reducing delivery time, and responding quickly to customer's service requests, and thus further enhance consumer satisfaction. Finally, empathy quality has a positive impact on the consumer satisfaction of fresh food e-commerce logistics services. This result is consistent with the viewpoint put forward by Parasuraman et al. [33] in their own research. Consumers need more detailed product information in the process of buying fresh products. Fresh products are prone to stale quality risks, and consumers need more intimate and meticulous service guidance and after-sales service to deal with hidden dangers. Merchants must improve the empathy service quality from the perspective of customers, provide more intimate and meticulous consumer services, and better food, transaction, privacy, and other aspects of security, in order to improve consumers' satisfaction with fresh food e-commerce logistics services.

In addition, according to the analysis results, delivery quality and information quality have no significant impact on consumer satisfaction. In view of this result, this study will be discussed as follows. For delivery quality, at present, the main large-scale fresh food e-commerce enterprises (such as Amazon Fresh in the United States and HEMA Fresh in China) adopted the service mode of self-built logistics, in order to realize the comprehensive management and control of the whole supply chain and logistics service with high quality, high standards, and standardization [32]. In this context, the widespread use of cold chain distribution has become an inevitable trend. Customers can also specify the 'home delivery' time and 'personal delivery' service. This can also ensure the integrity and cleanliness of the packaging of the goods throughout the logistics process. Therefore, in the high-standard and standardized logistics service management and control system, the result that delivery service quality has no significant impact on the consumer satisfaction of fresh food e-commerce logistics services has been reasonably explained. For information quality, online shopping consumers have mastered internet applications. When encountering brand-new application products and models, consumers will learn and apply them quickly. Therefore, the acquisition and tracking of product supply information, logistics distribution information, and other related information is no longer a difficult task. In addition, the relevant provisions of internet transactions require businesses to make information transparent and provide timely and accurate information. This has become a consensus in the industry. The insignificant impact of the information service quality on the consumer satisfaction in this research has also been reasonably explained. Figure 2 presents the results of the delivery and information service quality on consumer satisfaction, which are not statistically significant. However, the positive impact relationship (the estimated coefficients of the two are +0.03 and +0.09 , respectively) is consistent with our hypothesis. This positive effect relationship was also verified in the studies of Hong et al. [31], Bienstock et al. [34], Lin et al. [38], and Fernandes et al. [39].

Secondly, consumers' perceived importance of last-mile logistics services has a positive and significant impact on consumer satisfaction. Thus, it is demonstrated that the hypothesis $\mathrm{H} 2$ is accepted. This result is consistent with the views put forward by Kim and Lim [40], Kuo et al. [42], and Lai et al. [60]. Consumers' perceived importance of last-mile logistics services has a significant positive impact on consumer satisfaction. Last-mile logistics is the only link that directly contacts consumers. It involves various important pieces of personal information, such as the consumer's personal address and contact information. As a result, consumers' perceptions of last-mile logistics services are more important and will positively affect their satisfaction with fresh food e-commerce logistics services. This is similar to the situation in which the more a person values a thing, the higher is the sense of pleasure and accomplishment or the higher is the degree of recognition of oneself is similar, when the thing is over (being completed). Therefore, when fresh food e-commerce successfully completed the last-mile logistics service, consumers' perceived importance of the last-mile logistics service had a significant positive impact on consumers' satisfaction. 
Thirdly, this study verified the moderating effect of the last-mile logistics service consumers' perceived importance on the influence relationship between the quality of fresh food e-commerce logistics service and customer satisfaction. Only from the perspective of the model as a whole does the consumer's perceived importance of last-mile logistics services have a moderating effect. This point is consistent with Wolfram and Gratton [44], Kim [45], Jeong [46], and Iseke [48], who proposed that perceptual importance has a moderating effect. The moderating variable, perceived importance, has a significant and stable adjustment effect on some evaluation factors. However, its regulating effect has limitations. Because of this unstable situation, we believe that the research results supporting $\mathrm{H} 3$ are mixed. Thus, $\mathrm{H} 3$ is deemed to be not fully accepted.

Finally, through the analysis of the different evaluation dimensions, companies need to pay more attention to the following quality factors. Firstly, with regard to information quality, companies should pay more attention to the two aspects of "Logistics delivery information can be queried in time" and "Logistics delivery information can be easily queried". Enterprises need to increase the resource allocation and improve the relevant technical levels, and they can provide more user-friendly information acquisition services through technological upgrades. Secondly, with regard to timeliness quality, companies should pay more attention to "The delivery time of the goods to the user is very short". Enterprises can adjust the distribution plan, optimize the design of the package distribution route, and introduce more advanced data analysis and processing equipment, so as to provide the fastest and most optimized distribution plan in real time. In the end, the time to deliver goods to users is compressed to its shortest. Finally, with regard to empathy quality, companies should pay more attention to the "Logistics service providers should give sympathy and comfort and provide good return services when necessary" and "Give full help and support and protect the privacy of customers' personal information" aspects. Enterprises need to enhance the empathy of customer service personnel, strengthen the professional business training of staff, and provide customers with adequate security. In addition, the process of accepting returns and exchanges should be simplified to the greatest extent, so that consumers can feel a warmer and more considerate service experience.

\subsection{Theoretical Contribution and Immediate Significance}

This thesis provides important academic value for the research in this field. First, based on the existing e-commerce logistics research, this study offers further understanding of the important factors that affect customer satisfaction in fresh food e-commerce logistics services. The study enriches and supplements the empirical research in this field. Second, based on the existing logistics service quality evaluation system, a more comprehensive service quality evaluation system is proposed. Finally, most studies in the field of e-commerce only demonstrated the correlation between consumers' perceived importance factors and consumer satisfaction $[41,43,44]$. This study demonstrates that consumers' perceived importance factors have a significant positive causal relationship to consumer satisfaction.

Moreover, the following practical contributions have been made. First, this study provides academic literature with a reference value for fresh food e-commerce companies and online or offline retailers who use fresh food e-commerce. Through the findings, fresh food e-commerce enterprises can determine which service quality can improve customer satisfaction and can enhance customers' willingness to repurchase. Second, fresh food e-commerce companies can more accurately understand the quality items that they need to pay attention to in their last-mile logistics service. Moreover, this study provides a decision-making reference for the operation service mode and resource optimization allocation of fresh food e-commerce enterprises. Finally, fresh food e-commerce companies can refer to the research results and make corresponding improvements to the quality of logistics services, so that consumers can enjoy higher-quality logistics services and obtain indirect benefits. 


\subsection{Limitations and Future Research}

The research of this subject is limited by the authors' theoretical knowledge, social research capabilities, time, and other factors. Several deficiencies exist. First, this study was influenced by theoretical knowledge, and thus the impact factors selected in this topic have certain limitations. Simultaneously, this survey only conducted empirical research on the logistics of fresh products, and the broad applicability of the index system needs to be further verified. Second, this study only evaluated fresh logistics services from the consumer's perspective, but it did not study the perspectives of e-commerce companies and third-party logistics service providers.

Moreover, although the sample size used in this study met the research needs in a statistical sense, there were limitations when faced with a wide range of realms, a large population, and a diverse regional culture. In future research, the total amount of data collected must be expanded, and the proportion of sampling must be reasonably allocated to each region during the data collection. Moreover, the representativeness and diversity of the data must be increased.

Finally, we admit that the data obtained are cross-sectional and hypothetical because of the use of stated preference surveys. Future research can conduct investigations over a long period, or by comparing data from general and special environments to analyze the changes in the customer satisfaction of fresh food e-commerce logistics services under other circumstances.

Author Contributions: Conceptualization: Y.J.; P.L., S.L.; methodology: Y.J.; P.L.; S.L.; formal analysis: Y.J.; P.L.; S.L., data curation: S.L.; X.W., writing—original draft preparation: Y.J.; C.-H.C.; X.W.; K.F.Y.; writing-review and editing: K.F.Y.; P.L.; visualization: Y.J.; supervision: P.L., C.-H.C. All authors have read and agreed to the published version of the manuscript.

Funding: This research was funded by the 4th Educational Training Program for the Shipping, Port and Logistics from the Ministry of Oceans and Fisheries: 2021.

Conflicts of Interest: The authors declare no conflict of interest.

\section{References}

1. China Federation of Logistics and Purchasing. China Logistics Development Report (2017-2018); China Federation of Logistics and Purchasing: Beijing, China, 2019.

2. Arvidsson, N. The milk run revisited: A load factor paradox with economic and environmental implications for urban freight transport. Transp. Res. Part A Policy Pract. 2013, 51, 56-62. [CrossRef]

3. Brown, J.R.; Guiffrida, A.L. Carbon emissions comparison of last mile delivery versus customer pickup. Int. J. Logist. Res. Appl. 2014, 17, 503-521. [CrossRef]

4. Guritno, A.D.; Fujianti, R.; Kusumasari, D. Assessment of the Supply Chain Factors and Classification of Inventory Management in Suppliers' Level of Fresh Vegetables. Agric. Agric. Sci. Procedia 2015, 3, 51-55. [CrossRef]

5. Gu, W.; Kongju National University; Bao, P.; Lee, J.-H. A Study on the Continuance Intention of O2O Fresh Agricultural Products E-Commerce. J. Ind. Distrib. Bus. 2019, 10, 35-44. [CrossRef]

6. Prajapati, D.; Harish, A.R.; Daultani, Y.; Singh, H.; Pratap, S. A Clustering Based Routing Heuristic for Last-Mile Logistics in Fresh Food E-Commerce. Glob. Bus. Rev. 2020, 1-14. [CrossRef]

7. Maruyama, M.; Wu, L.; Huang, L. The modernization of fresh food retailing in China: The role of consumers. J. Retail. Consum. Serv. 2016, 30, 33-39. [CrossRef]

8. Lin, W.; Xu, A.; Zheng, Q.; Ke, L.; Lin, J. Influence of customer perceived value on the online shopping intention of aquatic products under B2C E-commerce. J. Discret. Math. Sci. Cryptogr. 2018, 21, 1189-1192. [CrossRef]

9. Huang, L.; Liu, P. Key Technologies and Alogrithms' Application in Agricultural Food Supply Chain Tracking System in Ecommerce. In Proceedings of the Computer and Computing Technologies in Agriculture VII, CCTA 2013, Beijing, China, 18-20 September 2013; Volume 420, pp. 269-281. [CrossRef]

10. Neghabadi, P.D.; Samuel, K.E.; Espinouse, M.-L. Systematic literature review on city logistics: Overview, classification and analysis. Int. J. Prod. Res. 2019, 57, 865-887. [CrossRef]

11. Taniguchi, E.; Thompson, R.G.; Yamada, T. New Opportunities and Challenges for City Logistics. Transp. Res. Procedia 2016, 12, 5-13. [CrossRef]

12. Hu, W.; Dong, J.; Hwang, B.-G.; Ren, R.; Chen, Z. A Scientometrics Review on City Logistics Literature: Research Trends, Advanced Theory and Practice. Sustainability 2019, 11, 2724. [CrossRef] 
13. Viu-Roig, M.; Alvarez-Palau, E.J. The Impact of E-Commerce-Related Last-Mile Logistics on Cities: A Systematic Literature Review. Sustain. J. Rec. 2020, 12, 6492. [CrossRef]

14. Yuen, K.F.; Wang, X.; Ng, L.T.W.; Wong, Y.D. An investigation of customers' intention to use self-collection services for last-mile delivery. Transp. Policy 2018, 66, 1-8. [CrossRef]

15. Alves, R.; Lima, R.D.S.; De Sena, D.C.; De Pinho, A.F.; Holguín-Veras, J. Agent-Based Simulation Model for Evaluating Urban Freight Policy to E-Commerce. Sustain. J. Rec. 2019, 11, 4020. [CrossRef]

16. Rai, H.B.; Verlinde, S.; Macharis, C. Unlocking the failed delivery problem? Opportunities and challenges for smart locks from a consumer perspective. Res. Transp. Econ. 2019, 100753. [CrossRef]

17. Holguín-Veras, J.; Leal, J.A.; Sánchez-Diaz, I.; Browne, M.; Wojtowicz, J. State of the art and practice of urban freight management. Transp. Res. Part A Policy Pract. 2020, 137, 360-382. [CrossRef]

18. Rudolph, C.; Gruber, J. Cargo cycles in commercial transport: Potentials, constraints, and recommendations. Res. Transp. Bus. Manag. 2017, 24, 26-36. [CrossRef]

19. Arnold, F.; Cardenas, I.; Sörensen, K.; Dewulf, W. Simulation of B2C e-commerce distribution in Antwerp using cargo bikes and delivery points. Eur. Transp. Res. Rev. 2017, 10, 2. [CrossRef]

20. Zhao, L.; Li, H.; Li, M.; Sun, Y.; Hu, Q.; Mao, S.; Li, J.; Xue, J. Location selection of intra-city distribution hubs in the met-rointegrated logistics system. Tunn. Undergr. Space Technol. 2018, 80, 246-256. [CrossRef]

21. Wang, Y.; Zhang, D.; Liu, Q.; Shen, F.; Lee, L.H. Towards enhancing the last-mile delivery: An effective crowd-tasking model with scalable solutions. Transp. Res. Part E Logist. Transp. Rev. 2016, 93, 279-293. [CrossRef]

22. Kafle, N.; Zou, B.; Lin, J. Design and modeling of a crowdsource-enabled system for urban parcel relay and delivery. Transp. Res. Part B Methodol. 2017, 99, 62-82. [CrossRef]

23. Kin, B.; Spoor, J.; Verlinde, S.; Macharis, C.; Van Woensel, T. Modelling alternative distribution set-ups for fragmented last mile transport: Towards more efficient and sustainable urban freight transport. Case Stud. Transp. Policy 2018, 6, 125-132. [CrossRef]

24. Zhang, Y.; Sun, L.; Hu, X.; Zhao, C. Order consolidation for the last-mile split delivery in online retailing. Transp. Res. Part E Logist. Transp. Rev. 2019, 122, 309-327. [CrossRef]

25. Fancello, G.; Paddeu, D.; Fadda, P. Investigating last food mile deliveries: A case study approach to identify needs of food delivery demand. Res. Transp. Econ. 2017, 65, 56-66. [CrossRef]

26. Chen, Q.; Conway, A.; Cheng, J. Parking for residential delivery in New York City: Regulations and behavior. Transp. Policy 2017, 54, 53-60. [CrossRef]

27. Kedia, A.; Kusumastuti, D.; Nicholson, A. Establishing Collection and Delivery Points to Encourage the Use of Active Transport: A Case Study in New Zealand Using a Consumer-Centric Approach. Sustain. J. Rec. 2019, 11, 6255. [CrossRef]

28. Köster, F.; Ulmer, M.W.; Mattfeld, D.C.; Hasle, G. Anticipating emission-sensitive traffic management strategies for dynamic delivery routing. Transp. Res. Part D Transp. Environ. 2018, 62, 345-361. [CrossRef]

29. Alberti-Alhtaybat, L.V.; Al-Htaybat, K.; Hutaibat, K. A knowledge management and sharing business model for dealing with disruption: The case of Aramex. J. Bus. Res. 2019, 94, 400-407. [CrossRef]

30. Huang, Y.-K.; Kuo, Y.-W.; Xu, S.-W. Applying Importance-performance Analysis to Evaluate Logistics Service Quality for Online Shopping among Retailing Delivery. Int. J. Electron. Bus. Manag. 2009, 7, 128-136.

31. Hong, W.; Zheng, C.; Wu, L.; Pu, X. Analyzing the Relationship between Consumer Satisfaction and Fresh E-Commerce Logistics Service Using Text Mining Techniques. Sustain. J. Rec. 2019, 11, 3570. [CrossRef]

32. LingYu, M.; Lauren, C.; Zhijie, D. Strategic Development of Fresh E-Commerce with Respect to New Retail. In Proceedings of the 2019 IEEE 16th International Conference on Networking, Sensing and Control (ICNSC), Banff, AB, Canada, 9-11 May 2019; pp. 373-378.

33. Parasuraman, A.; Zeithaml, V.A.; Berry, L. SERVQUAL: A multiple-item scale for measuring consumer perceptions of service quality. J. Retail. 1988, 64, 12-40.

34. Bienstock, C.C.; Royne, M.B.; Sherrell, D.; Stafford, T.F. An expanded model of logistics service quality: Incorporating logistics information technology. Int. J. Prod. Econ. 2008, 113, 205-222. [CrossRef]

35. Bienstock, C.C.; Mentzer, J.T.; Bird, M.M. Measuring physical distribution service quality. J. Acad. Mark. Sci. 1997, 25, 31. [CrossRef]

36. Mentzer, J.T.; Flint, D.J.; Hult, G.T.M. Logistics Service Quality as a Segment-Customized Process. J. Mark. 2001, 65, 82-104. [CrossRef]

37. Mentzer, J.T.; Flint, D.J.; Kent, J.L. Developing a logistics service quality scale. J. Bus. Logist. 1999, 20, 9-32.

38. Lin, Y.; Luo, J.; Cai, S.; Ma, S.; Rong, K. Exploring the service quality in the e-commerce context: A triadic view. Ind. Manag. Data Syst. 2016, 116, 388-415. [CrossRef]

39. Fernandes, D.W.; Moori, R.G.; Filho, V.A.V. Logistic service quality as a mediator between logistics capabilities and customer satisfaction. Rev. Gestão 2018, 25, 358-372. [CrossRef]

40. Kim, S.Y.; Lim, Y.J. Consumers' Perceived Importance of and Satisfaction with Internet Shopping. Electron. Mark. 2001, 11, 148-154. [CrossRef]

41. Taplin, R.H. Competitive importance-performance analysis of an Australian wildlife park. Tour. Manag. 2012, 33, 29-37. [CrossRef]

42. Kuo, S.-Y.; Yang, C.-C.; Lai, P.-L. Determining inland logistics service attributes: A case study of Chinese landlocked regions. Marit. Bus. Rev. 2020, 5, 313-330. [CrossRef] 
43. Mar, R.A.; Mason, M.F.; Litvack, A. How daydreaming relates to life satisfaction, loneliness, and social support: The importance of gender and daydream content. Conscious. Cogn. 2012, 21, 401-407. [CrossRef]

44. Wolfram, H.-J.; Gratton, L. Spillover Between Work and Home, Role Importance and Life Satisfaction. Br. J. Manag. 2012, 25, 77-90. [CrossRef]

45. Kim, S.J. A Study on the Causal Model of Waterpark Quality Evaluation Factors, Service Satisfaction, Repurchase Intention and Recommendation. Korean J. Bus. Adm. 2011, 24, 897-915.

46. Jeong, E. The Effects of User's Choice and Awareness of Importance of Choice in Community Social Services on User's Satisfaction-Focusing on Choice of Providing Organization and Providers. J. Soc. Serv. Study 2013, 4, 5-57.

47. Amorose, A.J.; Nolan-Sellers, W. Testing the moderating effect of the perceived importance of the coach on the relationship between perceived coaching feedback and athletes' perceptions of competence. Int. J. Sports Sci. Coach. 2016, 11, 789-798. [CrossRef]

48. Iseke, A. The Part-Time Job Satisfaction Puzzle: Different Types of Job Discrepancies and the Moderating Effect of Family Importance. Br. J. Ind. Relat. 2013, 52, 445-469. [CrossRef]

49. Thai, V.V. Logistics service quality: Conceptual model and empirical evidence. Int. J. Logist. Res. Appl. 2013, 16, 114-131. [CrossRef]

50. Rafiq, M.; Jaafar, H.S. Measuring customers' perceptions of logistics service quality of 3pl service providers. J. Bus. Logist. 2007, 28, 159-175. [CrossRef]

51. Xing, Y.; Grant, D.B.; McKinnon, A.C.; Fernie, J. Physical distribution service quality in online retailing. Int. J. Phys. Distrib. Logist. Manag. 2010, 40, 415-432. [CrossRef]

52. Kassim, N.M.; Abdullah, N.A. The effect of perceived service quality dimensions on customer satisfaction, trust, and loyalty in e-commerce settings. Asia Pac. J. Mark. Logist. 2010, 22, 351-371. [CrossRef]

53. Wang, X.; Yuen, K.F.; Wong, Y.D.; Teo, C.C. An innovation diffusion perspective of e-consumers' initial adoption of self-collection service via automated parcel station. Int. J. Logist. Manag. 2018, 29, 237-260. [CrossRef]

54. Boley, B.B.; McGehee, N.G.; Hammett, A.T. Importance-performance analysis (IPA) of sustainable tourism initiatives: The resident perspective. Tour. Manag. 2017, 58, 66-77. [CrossRef]

55. Kursunoglu, N.; Onder, M. Application of structural equation modeling to evaluate coal and gas outbursts. Tunn. Undergr. Space Technol. 2019, 88, 63-72. [CrossRef]

56. Davvetas, V.; Diamantopoulos, A.; Zaefarian, G.; Sichtmann, C. Ten basic questions about structural equations modeling you should know the answers to-But perhaps you don't. Ind. Mark. Manag. 2020, 90, 252-263. [CrossRef]

57. Hu, L.T.; Bentler, P.M. Cutoff criteria for fit indexes in covariance structure analysis: Conventional criteria versus new alternatives. Struct. Equ. Model. 1999, 6, 1-55. [CrossRef]

58. Hair, J.F. Multivariate Data Analysis; Kennesaw State University: Kennesaw, Georgia, 2009.

59. Fornell, C.; Larcker, D.F. Evaluating structural equation models with unobservable variables and measurement error. J. Mark. Res. 1981, 18, 39-50. [CrossRef]

60. Lai, P.-L.; Su, D.-T.; Tai, H.-H.; Yang, C.-C. The impact of collaborative decision-making on logistics service performance for container shipping services. Marit. Bus. Rev. 2020, 5, 175-191. [CrossRef] 